\title{
On the neurolinguistic nature of language abnormalities in Huntington's disease
}

\author{
CLAUS-W. WALLESCH, ROSE A FEHRENBACH \\ From the Departments of Neurology, University of Freiburg and University of Ulm, Federal Republic of \\ Germany
}

SUMMARY Spontaneous language of 18 patients suffering from Huntington's disease and 15 dysarthric controls suffering from Friedreich's ataxia were investigated. In addition, language functions in various modalities were assessed with the Aachen Aphasia Test (AAT). The Huntington patients exhibited deficits in the syntactical complexity of spontaneous speech and in the Token Test, confrontation naming, and language comprehension subtests of the AAT, which are interpreted as resulting from their dementia. Errors affecting word access mechanisms and production of syntactical structures as such were not encountered.

A participation of the basal ganglia not only in articulatory motor but also in language functions has repeatedly been proposed (for a review, see ref 1 ), and aphasia with vascular lesions of the left caudate and lenticular nuclei has been reported in a number of cases. $^{2-5}$

If, however, the basal ganglia were indeed crucial in language production, as has been stated by Brunner et $a l,{ }^{2}$ then degenerative diseases should also result in language deficits, and, if they were involved in linguistic processes, their chronic pathology should lead to abnormalities of phonological, lexical and/or syntactical aspects. If, on the other hand, only motor ${ }^{6}$ or motor and behavioural ${ }^{7}$ aspects of the use of language were concerned, these linguistic features should adapt in a rule-governed and systematic way to the nonlinguistic impairment.

The aim of the present study was to analyse the linguistic aspects of verbal behaviour in chronic basal ganglia disease. Although Parkinson's disease probably constitutes a more exact model of chronic basal ganglia pathology, ${ }^{8}$ we chose to investigate the effects of Huntington's disease upon language behaviour. It has been pointed out that Parkinsonian patients may suffer from a rather selective functional striatal dopamine deficit confined to the putaminal motor

Address for reprint requests: Dr C W Wallesch, Department of
Neurology, Hansastr. 9, D-7800 Freiburg FRG.

Received 19 May 1987 and in revised form 14 October 1987. Accepted 19 October 1987 striatum, ${ }^{8}$ whereas at least "the early brunt of Huntington's disease" seems to fall of the caudate nucleus, ${ }^{9}$ thus rather affecting the "complex" than the "motor" loop. 10

The main reason for our decision to investigate language functions in Huntington's chorea was that basal ganglia diseases lead to dysarthria in most cases, the consequences of which upon language production have to be taken into account. The effects upon communication of mainly hyperkinetic dysarthria in Huntington's disease and of cerebellar dysarthria in Friedreich's ataxia are quite similar (for a detailed description of these dysarthrias, see ref 11). Both are chronic, inherited diseases which lead to a slowly progressive motor speech impairment. Other than in Huntington's disease, impairments of higher mental functions in Friedreich's ataxia are only mild and seem to affect almost exclusively nonverbal aspects. ${ }^{1213}$ Deficits of language functions other than the consequences of dysarthria ${ }^{14}$ have not been reported in Friedreich's ataxia.

The pathology in Huntington's disease is not confined to the basal ganglia, but also involves the cerebral cortex. Therefore, deficits found in Huntington patients cannot be unequivocally related to striatal dysfunction. On the other hand, if certain linguistic processes were found to be spared in Huntington's disease, these may be considered as rather independent of basal ganglia functions. In a recent review of the literature ${ }^{7}$ it has indeed been proposed that linguistic functions proper such as word form access and production of sentence frames are not affected by basal ganglia disease. 
Patients

Eighteen patients suffering from Huntington's disease (nine male, nine female; mean age $41.8 \mathrm{yr}$ (SD 9.1); mean age at manifestation 35.8 yr (SD 7.7) were included. The diagnosis was made on the basis of the clinical findings and the family history. Five patients were still at work, five lived in psychiatric institutions, one in a home for aged and disabled persons, and the others within their families. Eleven patients received regular medication with tiapride- $\mathrm{HCl}$ and four a neuroleptic drug in addition. On the basis of the ShoulsonFahn rating scale ${ }^{15} 10$ patients were rated as early Huntington's disease (scores 1-2, mean age $37.2 \mathrm{yr}$, SD 5.9) and eight patients as advanced (scores $2 \cdot 5-3$, mean age $47.6 \mathrm{yr}$, SD9.4.

The Friedreich patients consisted of 15 subjects (four female, 11 male; mean age 42.4 yr (SD 11.6); mean duration of illness $23.4 \mathrm{yr}$ (SD 18.8)). The diagnosis was made on the basis of clinical criteria and positive family history. ${ }^{16-18}$ Eight patients were still employed, two of these in a sheltered workshop. All patients lived with their families. Patients with a visual acuity of less than 0.5 had been excluded.

\section{Methods}

Language assessment consisted of a detailed linguistic analysis of spontaneous language productions in an interview concerning the topics of the course of illness, personal, family and professional history and of the Aachen Aphasia Test. ${ }^{1920}$ The assessment was tape recorded and transcribed completely.

(1) LINGUISTIC ANALYSIS

The following parameters were included:

\section{(A) Phonological and semantic structure} syllables

words: word classes (nouns, full verbs, auxiliary verbs, modal verbs, adjectives, participles, adverbs, pronouns, prepositions, conjunctions, articles)

pauses: A pause was required to exceed 2 seconds and not to be situated at phrase boundaries.

units of information (UI): A UI was defined as a word or group of words necessary for the message contained in a statement which could not be subdivided into smaller

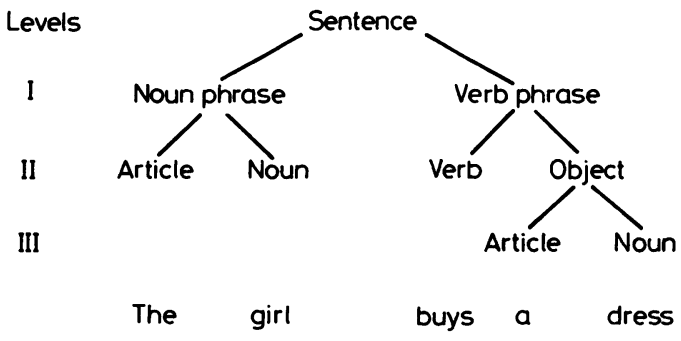

The sentence is organised in three levels

Fig Example of immediate constituent analysis.

The sentence is organised in three levels. propositionally relevant linguistic units and was not redundant. The parameter words/UI therefore gives an estimate of the density of information contained in a message.

perseverative errors: Any repetitions of productions (phonemes, words, phrase fragments and phrases) were included. phonemic paraphasias semantic paraphasias neologisms

stereotypies

(for definitions of paraphasias, neologisms, and stereotypies, see Huber et al. ${ }^{19}$

\section{(B) Syntactical structure}

sentences: A sentence was defined as a linguistically independent structure without syntactical relations with a superordinate form.

subordinate clauses

discontinued sentences: sentences broken off and remaining grammatically incomplete

agrammatical errors: defined as missing syntactical elements

paragrammatical errors: defined as erroneous or incongruous syntactical elements.

For an analysis of grammatical complexity of sentence productions an immediate constituent analysis was performed. ${ }^{21}$ This type of analysis is based on the assumption that sentences are hierarchically organised structures. The number of hierarchical levels necessary to derive the surface structure of the sentence was scored (fig). Subordinate claus ses were analysed as separate sentences.

(2) THE AACHEN APHASIA TEST (AAT)

The Aachen Aphasia Test ${ }^{1920}$ was specifically constructed for the assessment of aphasic patients. On the basis of this test patients with language abnormalities can be discriminated from normals, but whether the language deficit is aphasic in nature or not cannot be decided without further information.

The AAT consists of an analysis of the patients spontaneous language productions (the levels of communicative behaviour, articulation and prosody, automatised language, semantic, phonologic, and syntactic structure which are scored on scales of $0-5$ ), the Token Test in the version of Orgass, ${ }^{22}$ repetition of phonemes, words and sentences, written language (reading aloud and writing and word and sentence assembly to dictation), confrontation naming (including description of action pictures) and a multiple choice task for comprehension of spoken and written language. The scores can be transformed into percentile ranks and scores.

Thus, two quite different approaches towards assessment of linguistic performance were employed. The linguistic analysis of spontaneous speech aims at a description of the use of language within the context of actual communication, whereas in the AAT aspects of language behaviour are isolated by the introduction of artificial situations such as confrontation naming and repetition. As the deficits resulting from various language disorders affect the use of language in spontaneous speech and in formal test situations quite differently, inclusion of both types of assessment was considered imperative for the analysis of linguistic functions the present study aimed at. 
(3) PSYCHOMETRIC ASSESSMENT

A substantial number of patients were impaired in verbal communication and/or in the use of their hands. Therefore, only the scores in the Progressive Matrices $\mathrm{A}-\mathrm{C}^{\mathbf{2 3}}$ were included in the present analysis as a measurement of presence and degree of dementia.

(4) Statistical analysis was performed with the U-test and the $\mathrm{Chi}^{2}$ test according to Siegel. ${ }^{24}$ As the present study was designed as explorative, a large number of comparisons was included. Both diseases studied in the present investigation are comparatively rare and the number of subjects therefore limited. A correction for multiple comparisons was not conducted. The $p$ values derived from the U-test therefore do not constitute measures of significance.

\section{Results}

Table 1 indicates that the language production of the groups of patients suffering from Huntington's chorea and Friedreich's ataxia were indeed comparable.
Both groups produced similar mean numbers of syllables, words, sentences, made few agrammatical and paragrammatical errors and exhibited neither semantic nor phonemic paraphasias in their speech productions in an interview situation. Those phonological distortions which did occur could be explained as resulting from dysarthric phonetic disintegration. The psychometric assessment (table 2) revealed deficits of the Huntington patients in the Progressive Matrices and in the Token Test, naming and comprehension subtests of the AAT. The Friedreich patients performed normally except in those tasks which were affected by their dysarthria, namely communicative behaviour and repetition.

Other than in conversational speech, the Huntington patients produced semantic paraphasias in confrontation naming (table 3). Naming errors were very frequent with the advanced Huntington patients (on 90 out of 160 trials) and consisted mainly of fail-

Table 1 Results of linguistic analysis of spontaneous speech in patients with Huntington's disease and Friedreich's ataxia. (No difference reached $p<0.05$ in the $U$-test)

\begin{tabular}{|c|c|c|c|c|}
\hline \multirow[b]{2}{*}{$N$} & \multicolumn{2}{|c|}{ Huntington's disease } & \multicolumn{2}{|c|}{ Friedreich's ataxia } \\
\hline & Mean & $S D$ & Mean & $S D$ \\
\hline $\begin{array}{l}\text { Syllables/min } \\
\text { Unintellegible syll } / 100 \\
\text { Words/min } \\
\text { UI/min } \\
\text { Pauses/min } \\
\text { Sentences/min } \\
\text { Subordinate clauses } / 10 \text { sent } \\
\text { Discontinued } / 10 \text { sentences } \\
\text { Agrammatical errors } 10 \text { sent } \\
\text { Paragramm errors } / 10 \text { sent } \\
\text { Phonemic paraph/100 syll } \\
\text { Semantic paraph } / 100 \text { words } \\
\text { Stereotypies/min } \\
\text { Perseverations } / 100 \text { words }\end{array}$ & $\begin{array}{r}155 \cdot 1 \\
3 \cdot 6 \\
110 \cdot 2 \\
44 \cdot 4 \\
2.3 \\
11 \cdot 0 \\
2.6 \\
1.8 \\
0.9 \\
1 \cdot 1 \\
0 \\
0 \\
0 \\
1.0\end{array}$ & $\begin{array}{r}52 \cdot 8 \\
5 \cdot 6 \\
43 \cdot 6 \\
16 \cdot 8 \\
2 \cdot 2 \\
3 \cdot 4 \\
1.9 \\
1 \cdot 3 \\
0 \cdot 6 \\
0 \cdot 8 \\
0 \\
0 \\
0 \\
0 \cdot 1\end{array}$ & $\begin{array}{r}155 \cdot 5 \\
6 \cdot 0 \\
103 \cdot 8 \\
42 \cdot 2 \\
1 \cdot 4 \\
10 \cdot 6 \\
2 \cdot 4 \\
1 \cdot 2 \\
0 \cdot 6 \\
0 \cdot 4 \\
0 \\
0 \\
0 \\
1 \cdot 4\end{array}$ & $\begin{array}{r}47.6 \\
6.5 \\
38.7 \\
19 \cdot 1 \\
1.8 \\
4.7 \\
1.6 \\
1.2 \\
0.7 \\
0.9 \\
0 \\
0 \\
0 \\
1.9\end{array}$ \\
\hline
\end{tabular}

Table 2 Results of psychometric assessment with the Aachen Aphasia Test (percentile ranks except spontaneous speech) and the Progressive Matrices A-C (No of correct solutions among 36 items). Comparison of Huntington's chorea and Friedreich's ataxia patients. $U$-Test

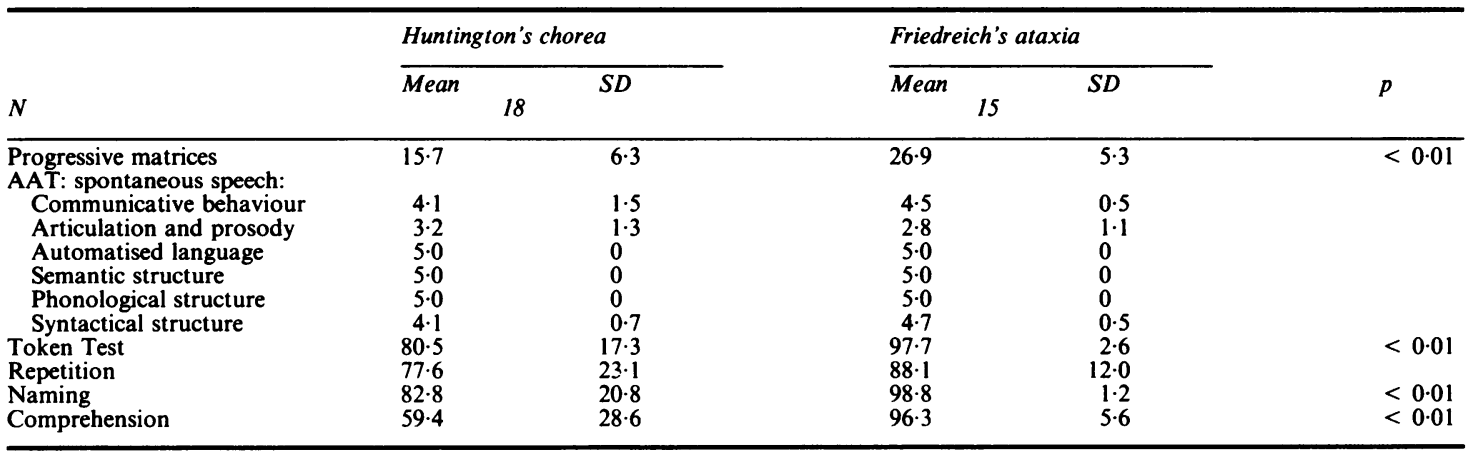


Table 3 Type and frequency of naming errors in early and advanced Huntington patients. Per cent of responses to 20 line drawings of common objects

\begin{tabular}{|c|c|c|c|c|c|}
\hline & $\begin{array}{l}\text { Semantically } \\
\text { related }\end{array}$ & $\begin{array}{l}\text { Visually } \\
\text { related }\end{array}$ & $\begin{array}{l}\text { Semantically plus } \\
\text { visually related }\end{array}$ & $\begin{array}{l}\text { Peseverated } \\
\text { or unrelated }\end{array}$ & $\begin{array}{l}\text { "Don't know" } \\
\text { or no response }\end{array}$ \\
\hline $\begin{array}{l}\text { Early (10) } \\
\text { Advanced (8) }\end{array}$ & $\begin{array}{r}4.5(9) \\
10.6(17)\end{array}$ & $\begin{array}{l}2 \cdot 5(5) \\
7 \cdot 5(12)\end{array}$ & $\begin{array}{l}1 \cdot 5(3) \\
4 \cdot 4(7)\end{array}$ & $\begin{array}{l}1.0(2) \\
5.6(9) \\
\mathrm{Chi}^{2}=6.61, \mathrm{p}>0.1\end{array}$ & $\begin{array}{r}3 \cdot 0(6) \\
28 \cdot 1(45)\end{array}$ \\
\hline
\end{tabular}

Table 4 Results of linguistic analysis of spontaneous speech. Comparison of 10 patients with early and of 8 patients with advanced Huntington's disease and of 9 patients with Friedreich's ataxia with mild and of 6 with marked dysarthria

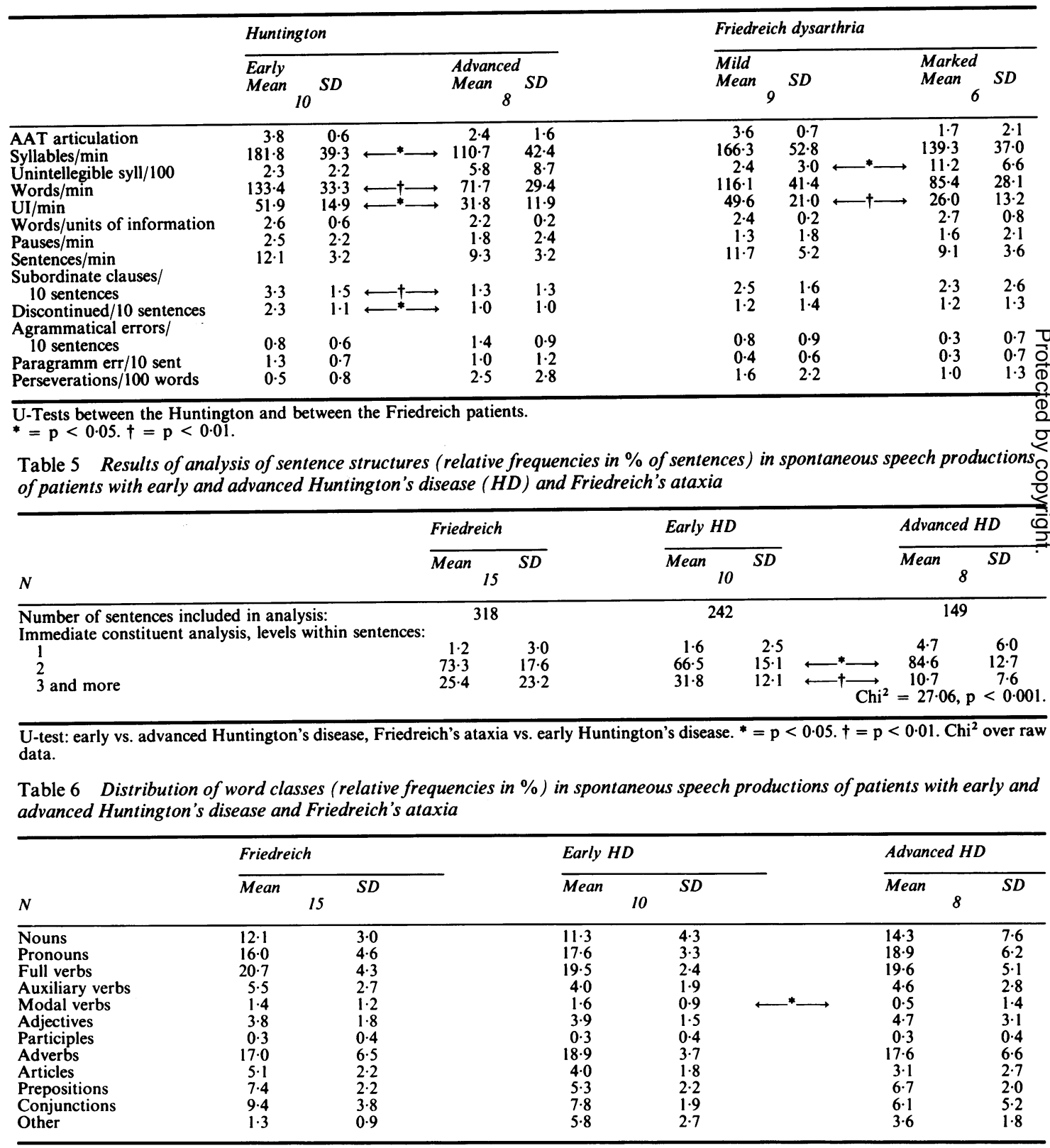

U-Test: early vs. advanced Huntington's disease; early Huntington's disease vs. Friedreich's ataxia.

$*=p<0.05$ 
Table 7 Results of psychometric assessment with the Aachen Aphasia Test and Progressive Matrices A-C. Comparison of patients with early and advanced Huntington's disease. U-Test

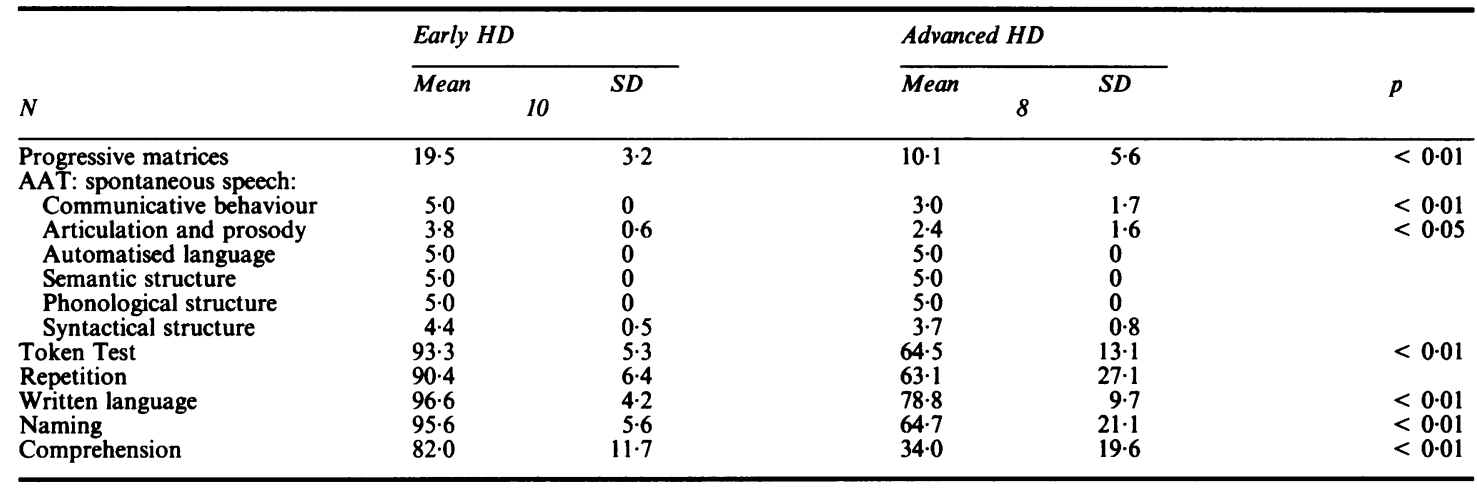

ures to produce a name at all and in smaller numbers of semantically and/or visually related misnamings.

In comparison with patients in the early stages of the disease, patients suffering from advanced chorea exhibited a decrease of verbal fluency (table 4). This can at least partly be explained on the basis of the presence of more severe dysarthria alone, as Friedreich patients showed a similar effect with an increasing degree of dysarthria. The information density as measured by words/unit of information remained rather unaffected by the advance of dysarthria in both diseases.

The number of subordinate clauses was found to be markedly lower in the advanced Huntington but not in the more severely dysarthric Friedreich cases. A significant decrease of syntactical complexity was also found in the immediate constituent analysis (table 5).

A comparison of word classes occurring in the utterances of early and advanced Huntington and the Friedreich patients (table 6) reveals remarkably similar distributions. The only difference among the groups was a reduction in the use of modal verbs in the productions of the advanced Huntington patients, which phenomenon again can be attributed to a decrease of syntactical complexity.

There were substantial differences between the results of early and advanced Huntington patients in the AAT (table 7). Advanced cases were impaired in the Token Test and in the naming and comprehension subtests, which, other than impairments of the advanced group in the communicative behaviour and articulation and prosody levels of spontaneous speech analysis cannot be related to these patients' more severe dysarthria, as effects of dysarthria are excluded by the scoring system. In the Token Test and confrontation naming the performance of the early Huntington patients was comparable to that of the Friedreich's controls (compare table 2).

\section{Discussion}

Huntington's chorea undisputedly leads to dementia, which may cause language abnormalities. Bruyn ${ }^{25}$ stated that there may be patients suffering from this disease without motor symptoms but that there are none without psychopathologic signs. At least in the early stages the higher mental function impairments seem to be dominated by memory deficits. ${ }^{26}$ Other neuropsychological symptoms occurring early in the course of disease are deficits of attention and of frontal lobe functions, such as concept formation ${ }^{27}$ and of visual perception. ${ }^{28}$ Language functions have been reported to remain relatively undisturbed with the advance of disease. ${ }^{2629}$ However, the effects of dysarthric motor speech impairment and dementia upon language in Huntington patients have not yet been analysed in detail.

Meggendorfer ${ }^{30}$ commented in 1923 upon the discrepancy between the deficit of Huntington patients in confrontation naming and their quite intact word access in conversation. The present investigation demonstrates that in their spontaneous speech patients with chorea make few if any linguistic errors. No semantic paraphasias and very few agrammatical and paragrammatical errors occurred, in both Huntington and Friedreich patients. The distribution of word classes was virtually the same in patients suffering from both diseases, and only the frequency of modal verbs (in the English language, for example, can, must, and shall and will with the exception of their use in the future tenses) decreased with the advance of Huntington's disease. The number of pauses within phrases (a parameter of word access problems) did not differ remarkably between Huntington and Friedreich patients and among Huntington patients with the advance of the disease. Those differences which did occur between early and 
advanced Huntington patients in their spontaneous speech productions could either be related to the fluency of their productions and were found with Friedreich's dysarthria also, or to the syntactical complexity of the sentence structure. We suggest that this reduction of syntactical complexity, which was demonstrated in the immediate constituent analysis and in a less frequent use of constructions containing subordinate clauses, does not reflect an aphasic impairment of the language system but rather a pragmatic/conceptual deficit resulting from dementia. Similar results have been reported for patients with syndromes of dementia other than Huntington's disease by Irigary ${ }^{31}$ and Blanken et al. ${ }^{32}$

If it is suggested that Huntington's chorea does not lead to aphasic symptoms, the deficits of Huntington patients in an aphasia test have to be explained. These occurred in three subtests, namely the Token Test, confirmation naming and in language comprehension. It has been shown that Token Test performance relies on the integrity of quite complex cognitive functions. ${ }^{33}$ Demented and oligophrenic patients were found to be markedly impaired in the Token Test as well as in a linguistically structured multiple choice language comprehension test as included in the AAT. ${ }^{34}$

Similarly, an impairment of confrontation naming cannot per se be regarded as a symptom of an aphasic disorder. In demented patients of aetiologies other than Huntington's chorea semantically and visually related misnamings ${ }^{35-37}$ have been reported. Errors in confrontation naming as produced by the Huntington patients in the present investigation seem to be a regular feature of dementia regardless of aetiology.

The present study therefore was unable to produce evidence that the language impairments in Huntington's disease are aphasic in nature. The instrumental mechanisms of language (word access and the generation of syntactical structures) remain rather intact with the advance of disease. These findings are consistent with a recent reanalysis of the data concerning basal ganglia aphasia. Wallesch and Papagno ${ }^{7}$ suggested that the underlying functional pathology of the language deficits encountered with acute vascular lesions of the left caudate and lenticular nucleus is probably not located in the language system as such, that is, word form access and grammaticalisation are not affected.

This article is dedicated to the memory of Woody Guthrie, a victim of Huntington's Disease. The investigations were supported by the Deutsche Forschungsgemeinschaft, grants $\mathrm{Br} 736$ and $\mathrm{Wa} 509$. The authors thank Prof Dr H Oepen, Dr G Oepen, Dr G Blanken, and Dr J C Haas for cooperation and advice.

\section{References}

1 Wallesch CW, Wyke MA. Subcortical aphasia. In: Newman S, Epstein R, eds. Dysphasia. Edinburgh: Churchill-Livingstone 1985:182-97.

2 Brunner RJ, Kornhuber HH, Seemüller E, Suger G, Wallesch CW. Basal ganglia participation in language pathology. Brain Lang 1982;16:281-99.

3 Cappa SF, Cavallotti G, Guidotti M, Papagno C, Vignolo LA. Subcortical aphasia: two clinical-CT scan correlation studies. Cortex 1983;15:121-30.

4 Puel M, Demonet JF, Cardebat D, et al. Aphasies sous-corticales. Rev Neurol (Paris) 1984;140:695-710.

5 Wallesch CW. Two syndromes of aphasia occurring with ischemic lesions of the left basal ganglia. Brain Lang 1985;25:357-61.

6 Marsden $\mathrm{CD}$. The mysterious motor function of the basal ganglia. The Robert Wartenberg Lecture. Neurology 1982;35:514-39.

7 Wallesch CW, Papagno C. Subcortical aphasia. In: Rose FC, Whurr R, Wyke MA, eds. Aphasia. London: Cole and Whurr (in press).

8 Marsden CD. Discussion remark. In: Ciba Foundation Symposium 107: Functions of the basal ganglia. London: Pitman, 1984:219.

9 Marsden CD. Discussion remark. In: Ciba Foundation Symposium 107: Functions of the basal ganglia. London: Pitman, 1984:223.

10 Alexander GE, DeLong MR, Strick PL. Parallel organization of functionally segregated circuits linking basal ganglia and cor-o tex. In: Cowan WM, Shooter EM, Stevens CF, Thompson RFŌ eds. Annual Review of Neuroscience, vol. 9. Palo Alto, Annuad Reviews Inc., 1986:357-82.

11 Darley FL, Aronson AE, Brown JR. Motor Speech Disorders Philadelphia: Saunders, 1975.

12 Geoffroy G, Barbeau A, Breton G. Clinical description an roentgenologic evaluation of patients with Friedreich's ataxi Can J Neurol Sci 1976;3:279-86.

13 Fehrenbach RA, Wallesch CW, Claus D. Neuropsychologi deficits in Friedreich's ataxia. Arch Neurol 1984;41:306-8.

14 Joanette Y, Dudley JG. Dysarthric symptomatology of $\infty$ Friedreich's ataxia. Brain Lang 1980;10:39-50.

15 Shoulson I, Fahn S. Huntington Disease: Clinical care and evaluation. Neurology 1979;29:1-3.

16 Andermann E, Remillard GM, Goyer C, Blitzer L, Andermann F, Barbeau A. Genetic and family studies in Friedreich's ataxia. Can J Neurol Sci 1976;3:287-301.

17 Barbeau A. Friedreich's ataxia 1976: An overview. Can J Neurol Sci 1976;3:389-97.

18 Refsum S, Skre H. Neurological approaches to the inherited ataxias. Adv Neurol 1956;21:1-13.

19 Huber W, Poeck K, Weniger D, Willmes K. Der Aachener Aphasie Test. Göttingen: Hogrefe, 1983.

20 Huber W, Poeck K, Willmes K. The Aachen Aphasia Test. In: Rose FC, ed. Advances in Neurology, vol. 42. New York: Raven, 1984:291-304.

21 Pelz H. Linguistik für Anfänger, 2nd ed. Hamburg: Hoffmann und Campe, 1978.

22 Orgass B. Eine Revision des Token Tests. Diagnostica 1976;22:70-87.

23 Raven JC. Standard Progressive Matrices. London: Lewis, 1956

24 Siegel S. Nonparametric statistics for the behavioral sciences. Tokyo: McGraw Hill, 1956.

25 Bruyn GW. Huntington's Chorea: Historical, clinical and laboratory synopsis. In: Vinken PJ, Bruyn GW, eds. Handbook of Clinical Neurology, vol. 13. Amsterdam: North Holland, 1969:298-378.

26 Caine ED, Hunt RD, Weingartner H, Ebert MH. Huntington's dementia. Clinical and neuropsychological features. Arch Gen Psychiat 1978;25:377-84. 
27 Fedio P, Cox CS, Neophytides A, Canal-Frederick G, Chase TN. Neuropsychological profile of Huntington's disease, patients and those at risk. In: Chase TN, Wexler NS, Barbeau A, eds. Advances in Neurology, vol. 23. New York: Raven, 1979:239-55.

28 Moses JA, Golden CJ, Berger PA, Wisniewski AM. Neuropsychologic deficits in early, middle, and late stage Huntington's disease as measured by the Luria-Nebraska Neuropsychological battery. Int J Neurosci 1981;14:95-100.

29 Fisher JM, Kennedy JL, Caine ED, Shoulson I. Dementia in Huntington's Disease: a cross-sectional analysis of intellectual decline. Adv Neurol 1983;38:229-38.

30 Meggendorfer F. Die psychischen Störungen bei der Huntingtonschen Chorea: klinische und genealogische Untersuchungen. Z Neurol Psychiat 1923;87:1-50.

31 Irigary L. La langage des Déments. The Hague: Mouton, 1973.

32 Blanken G, Dittmann J, Haas JC, Wallesch CW. Spontaneous speech in senile dementia and aphasia. Implications for a neurolinguistic model of language production. Cognition 1987; 27:47-74.

33 Cohen R, Kelter S, Engel D, List G, Strohner H. Zur Validität des Token Tests. Nervenarzt 1976;47:357-61.

34 Schumacher R, Johannsen-Horbach H, Wallesch CW. Die Leistungen im Token Test und im "Drei-Figuren-Test" bei Aphasikern, Dementen und Debilen. Sprache-Stimme-Gehör 1983;7:133-6.

35 Rochford G. A study of naming errors in dysphasia and in demented patients. Neuropsychologia 1971;9:437-43.

36 Bayles KA, Tomoeda CK. Confrontation naming impairment in dementia. Brain Lang 1983;19:98-114.

37 Martin A, Fedio P. Word production and comprehension in Alzheimer's Disease: The breakdown of semantic knowledge. Brain Lang 1983;19:124-41. 